\title{
The Effect of Rotation Stirring on Macrosegregation in Bi-Sn Alloy
}

\author{
Yeni Muriani Zulaida ${ }^{1 *}$, Riyan Afrizal ${ }^{1}$ and Suryana Suryana $^{1}$ \\ ${ }^{1}$ Metallurgical Department Faculty of Engineering, Sultan Ageng Tirtayasa University, 42435 Cilegon, Indonesia
}

\begin{abstract}
Macrosegregation is a defect that difficult to avoid in a metal alloy made by casting method. Macrosegregation can cause decreasing in mechanical properties of casting products. It will reduce their performance in industrial application. Macrosegregation is convinced occur during solidification time in liquid alloy. In the early solidified, The solids move upward/downward in liquid alloy during solidification are considered to contribute on macrosegregation formation. This movement occur due to the density differences between the solid and the surrounding liquid. This research want to observe the effect of stirring on macrosegregation formation for interfering on the movement of initial solidified solid. Stiring with rotation method is applied in this experiment at certain temperature. The temperature and the rotation speed of stirring are varied to observe the effect of rotation stirring on macrosegregation formation. The mold is covered by insulation jacket and kept the bottom part opened in order to obtain the directionally solidification. The result shows that the rotation stirring can change the macrostructure of casting but in case of composition distribution, the macrosegregation still appear. Increasing the rotation stirring will rise solid crystals up and the macrosegregation become more uniform and the treatment is better if conducting at lower temperature.
\end{abstract}

\section{Introduction}

Macrosegregation is a compositional inhomogeneities at large scale compared with microsegregation and can affect to the properties of the casting.. The range in scale from millimeters to centirmeters. It is seen commonly in components made by all type of casting processes and in any materials. Macrosegregation cannot be mitigated through processing of the casting after solidification complete. It may occur during solidification time. The low diffusifity of solute in solid state may be the cause. It affects to different composition at next to interface and turn to be a density differences in liquid. Beckermann summarized that the cause of macrosegregation is relative movement or flow of segregated liquid and solid during solidificatin [1]. In this case gravity force lead an important role in macrosegregation process. Typical examples are dendrites settling in the bottom of ingots or coarse primary lamellae graphite floating on the top of large cast iron castings [2]. The main driving force of fluid flow during solidification is solidification contraction. Interdendritic liquid flow can cause higher consetration of solute than average composition in the earlier solidification [3]. External force, for example centrifugal casting [4], rotating and oscillating [5] can change the solute concentration in casting.

Macrosegregation start at microsegregation level during solidification. If consentration gradient at interface are developed significantly, the flow may occur to liquid at next to interface. This can cause a segregation in the macroscopic level known as macrosegergation.

In low solubility of solute in matriks, in this case solute $(\mathrm{Sn})$ dissolve into $\mathrm{Bi}$, the macrosegregation in stationary casting condition can be shown in Fig.1. The the grains of primary phase that suppose to disperse evenly throughout the ingot but instead are concentrated at the bottom of ingot, it may be occur when the primary phase that is formed at the initial stage of solidification, has higher density than the surrounding eutectic liquid and due to gravity force, the primary phase settle to the bottom of ingot [2]. This cause inhomogeneities of macrostructure in ingot and furthermore can affect to properties of casting product. The observation of the grain setlling for this alloy had been conducted in previous research [6]. The primary phase grain required some times for settling so when the cooling time was accelerated, the setlling time will decrease and the pile of primary phase grain become more higher and the size smaller.

Several attempts were made to reduce the effect of the structure differences in casting product. Previous researches explained, such as, additional the electromagnetic force during centrifugal casting in pipe product[4], rotation and oscillation method in Aluminium alloy[4] or cooling rate[6] as an attempt in order to decrease macrosegregation. In this research

*Corresponding author: yeni_m_zulaida@untirta.ac.id 
rotation method is used as one of attempt to decrease macrosegregation and homogenize the structure in macroscopic level. According the explanation in previous paragraph above, the alloy with low solubility of solute is used for observation on the effect of rotation.

In this work, rotation stirring method with lower rotation speed compared from previous research is applied in attempts to treat liquid during solidification in order to reduce the macrosegregation. The aim of this study was observing the effet of rotation stirring on the macrosegregation formation. Bi alloy with $30 \mathrm{wt}$ pct of $\mathrm{Sn}$ was used for facilitating the observation since primary $\mathrm{Bi}$ phase could be captured by macro camera clearly[7], as seen in Fig 1.

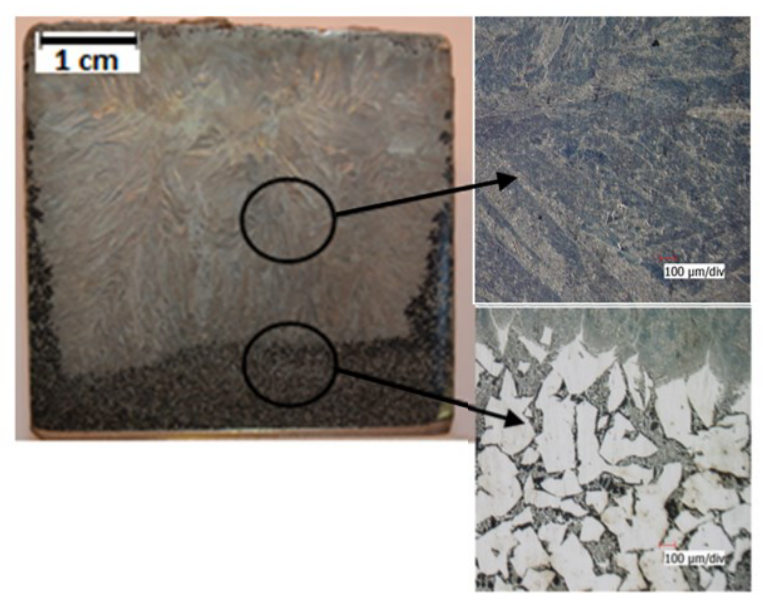

Fig.1 Primary phase (black) concentrated at the bottom ingot

\section{Experimental details}

This study use low melted alloy material, Sn-Bi Alloy. The alloy composition is $\mathrm{Bi}-30$ wt pet $\mathrm{Sn}$ prepared from 99.99 pet pure $\mathrm{Bi}$ and $\mathrm{Sn}$. This alloy reaction during solidification is considering on binary phase diagram of $\mathrm{Sn}-\mathrm{Bi}$ as seen in Fig.2. The alloy weight was approximately 600 gram and then it is placed into a cylinder steel mold with $4,5 \mathrm{~cm}$ in diameter. The mold is covered by insulation jacket on the top and all around of the mold but opened at the bottom in order to retard heat

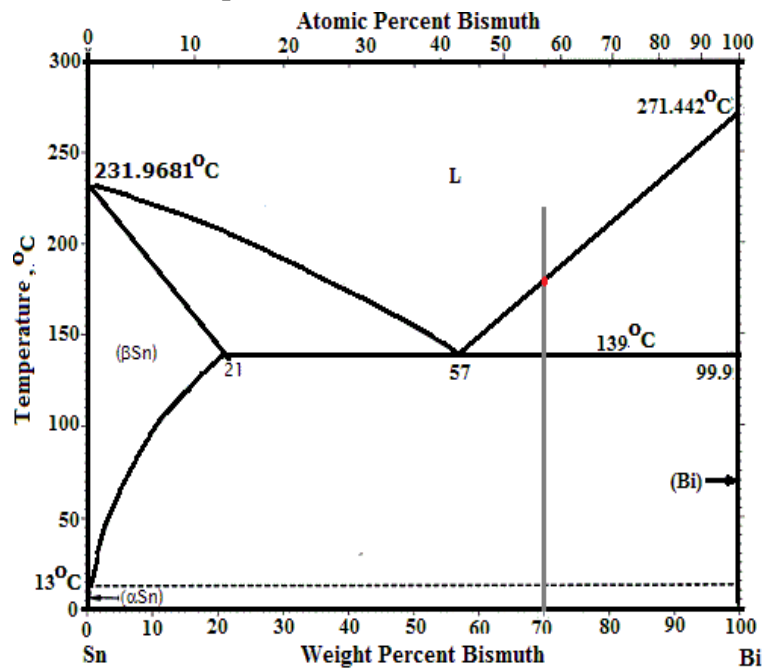

Fig.2. Sn-Bi phase diagram transfer from the top and side direction of metal mold but start to solidify from the bottom of the ingot.

In this experiment, the alloy then is melted using electric furnace. The melting point of alloy is $180^{\circ} \mathrm{C}$ and overheating around $50^{\circ} \mathrm{C}$. After that the molten metal filled mold is placed on rotation machine, as seen in

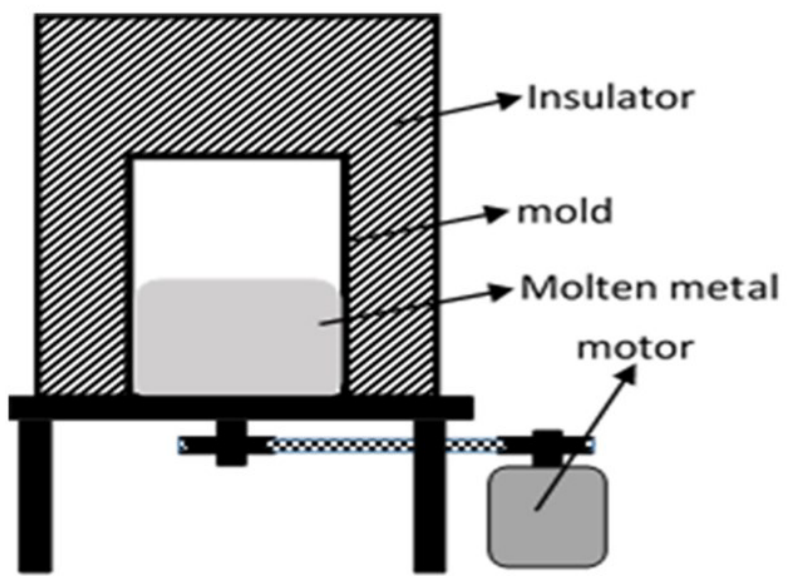

Fig.3. Schematic of rotating machine

Fig.3. And then at certain temperature, the molten is set to rotate. The speed rotations which are applied in this experiment were 50, 83 and $115 \mathrm{rpm}$. From preliminary experiment without rotation stirring, the required time of complete solidification can be obtained. The temperature changes can be measured using thermocouples that is connected with data logger. According this data, duration of rotation stirring is decided as 5 second. Rotation stirring is conducted at first in the liquid phase condition and the second in liquid-solid phase condition.

The observation of macrosegregation is held after the ingot solidify completely. The observation sampling sites located in the center of the ingot. The cylindrically Ingot is cut vertically and followed by surface preparation for macrostructure and microstructure observation. Macrostructure is observed using digital camera with macro lens and for microstructure using optical microscope. For consentration of solute distribution is analyzed using scaning electron microscope with energy disperse X-ray spectroscopy (SEM/EDS).

\section{Result and Discussion}

According phase diagram, when temperature reach liquidus line of Bi-30 wt pet $\mathrm{Sn}$ alloy, Bi primary phase start to nucleate. This nucleation should be occured at nucleation potential site, for example at mold wall. This initial phase has higher density than remain liquid and with enough time will move downward and settle in bottom of ingot. This mechanism cause the differences of distribution phase between upper side and down side of ingot. Rotation stirring process during solidification is expected can give additional force to move the $\mathrm{Bi}$ primary phase and spread it to all parts of casting. 


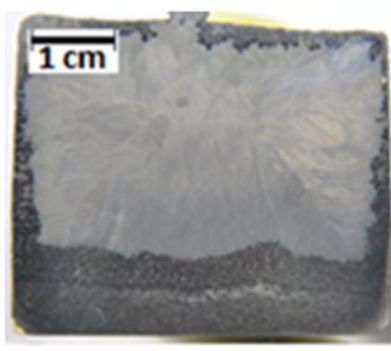

(a)

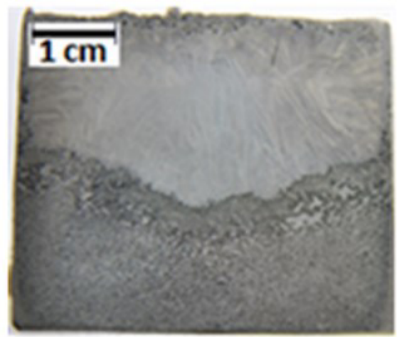

(c)

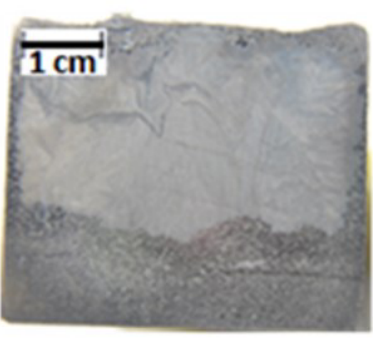

(b)

Fig.4. Macrostructure of ingot after rotation at (a) $50 \mathrm{rpm}$, (b) $83 \mathrm{rpm}$ and (c) $115 \mathrm{rpm}$
Fig.4. Macrostructure after rotation at (a) $50 \mathrm{rpm}$, (b) $83 \mathrm{rpm}$ and (c) $115 \mathrm{rpm}$

From this experiment, the macrostructure after rotation become different and it can be shown in Fig.4. Dark zone in the base of the ingot indicate Bi primary phase zone and the grey zone above show columnar grains of eutectic phase. Increasing the rotation speed is resulting primary phase consentration zone higher. Stirring using rotation method can generate a force inside remain eutectic liquid. This force move the liquid and push the primary phase toward mold wall and upward. The rotation speed influence on the height of the primary phase pile. In this study, $50 \mathrm{rpm}$ of rotation speed will produce the lowest force than two other rotation speed. With this condition it has not enough force to raise primary phase higher and the result the

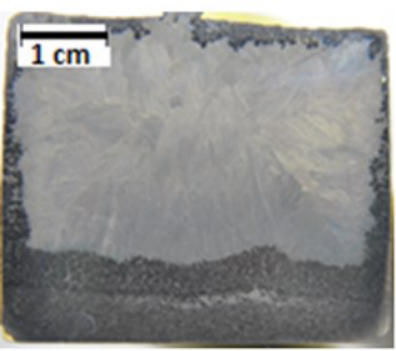

$50 \mathrm{rpm}$

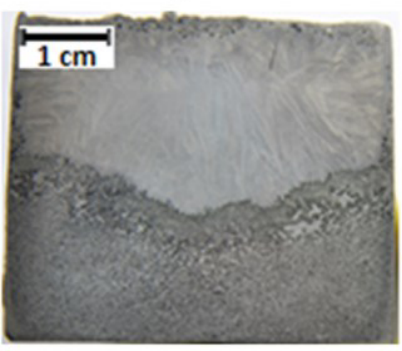

$115 \mathrm{rpm}$

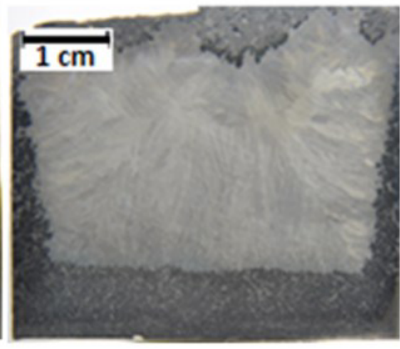

$50 \mathrm{rpm}$

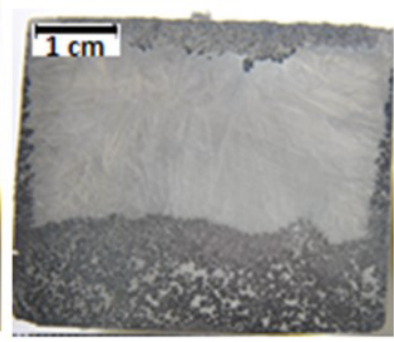

$115 \mathrm{rpm}$
Fig.5. The effect of temperature and rotation speed on macrostucture of Bi-Sn Alloy ingot height of primary phase pile is the lowest of all condition, eventhough The height of Bi primary phase zone is still higher compared with the ingot without rotation stirring. Above of primary phase region can be seen columnar structure.

The rotation speed can affect to the distance among one $\mathrm{Bi}$ primary grain to another grains. The distance is getting farther in $115 \mathrm{rpm}$ than two other lower rotation speed and the region become greater as well. The large of primary phase region is about $830 \mathrm{~mm}^{2}$ for $115 \mathrm{rpm}$ of speed and it is larger than rotation speed $50 \mathrm{rpm}$ and 83 rpm that only had $540 \mathrm{~mm}^{2}$ and $675 \mathrm{~mm}^{2}$.
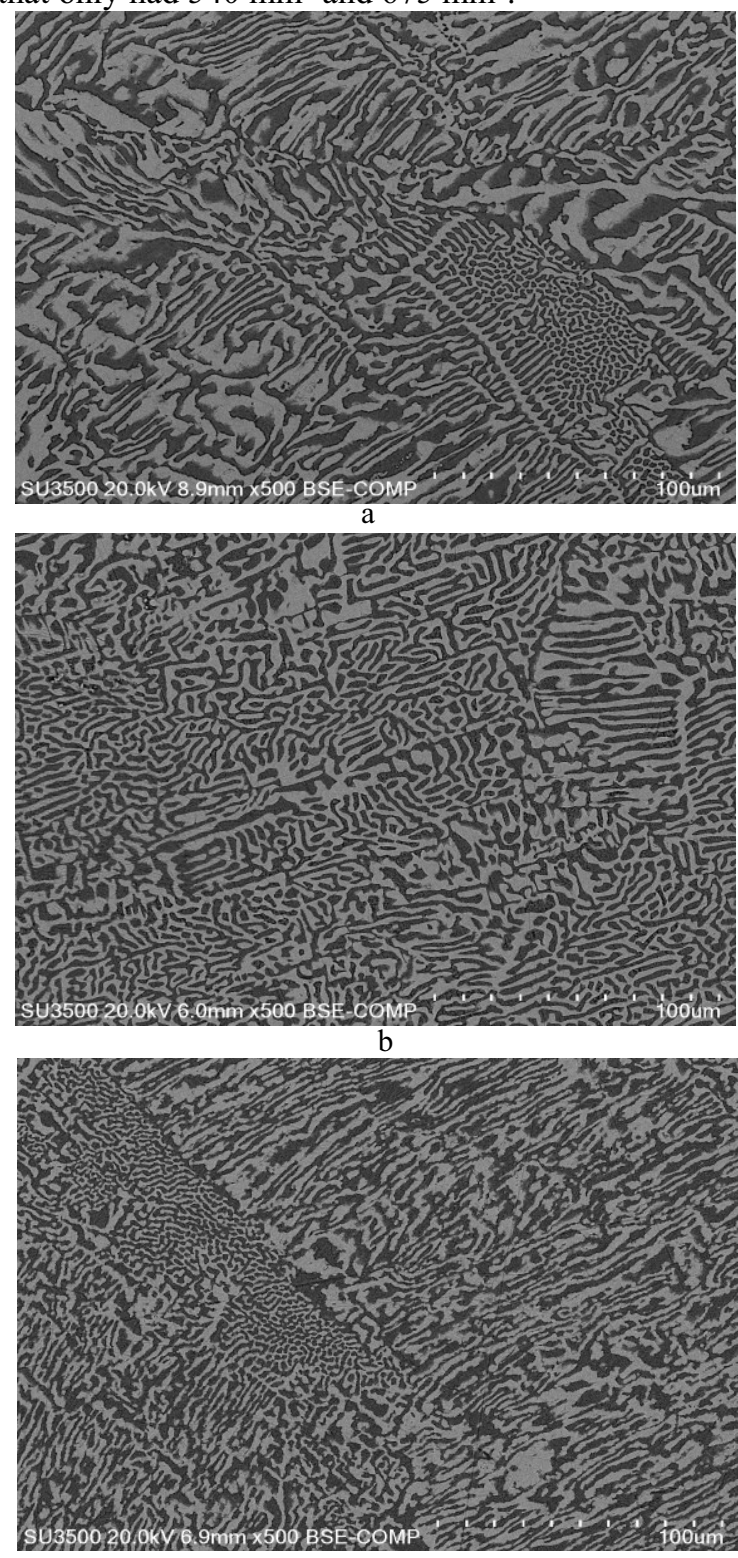

c

Fig.6. The microstructure of eutectic ini different rotation speed, a) $50 \mathrm{rpm}$, b) $85 \mathrm{rpm}$ and c) $115 \mathrm{rpm}$

The rotation temperature when the rotation stirring process conducted influence to the uniformity of macrostructure in ingot. Base on the distribution of phases in ingot, the rotation treatment is better conducting at lower temperature or in range solidification (solid-liquid phase) condition than liquid condition. Figure 5 show that in lower temperature 
result, the macrostructure is more uniform at the bottom of ingot, despite it still appear there is some regions that lack of primary phase among Bi primary zone. In spite of the proper speed and temperature selection is still necessary to get a good result. The rotation stirring cannot performe at the temperature is too low, this stirring process may induce the damage in the structure and lead tearing in the ingot.

Increasing rotation speed can indeed lift the primary phase zone become higher but the problem is, when the rotation speed keep increasing will result the height of the primary phase region at the center of ingot decrease and the consequences, the region like V-shape will appear in the ingot as seen in Figure 5 at stirring speed 115 and temperatur of stirring $150^{\circ} \mathrm{C}$. It is predicted that if the speed increase higher and higher. It is posibble that in the middle of the ingot will vacant with one of phase that will be form during solidification due to centrifugal force. This mechanism also can work in other alloy. So it is conclude that the treatment using rotation stirring was not effective to reduce macrosegregation if the rotation stirring speed too high.

The microstructure profile show the different result. In the Columnar structure consist eutectic phase as seen in Figure 6. From previous research by Olga Kusakova [8] summarized that cooling rate can influence on the microstructure formation. The different cooling rate could form an eutectic microstructure differently, such as, skeleton-like in Bi-Sn alloy or foil-cross section microstructure. Although in this experiment, the change of temperature during rotation treatment cannot be measured since technical matter, but from the microstructure result show, it is possible there that the cooling rate is the change during rotation stirring. It may occurs locally in ingot and cause different eutectic structure in microstructure level.

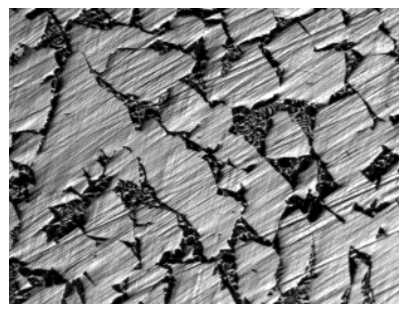

a

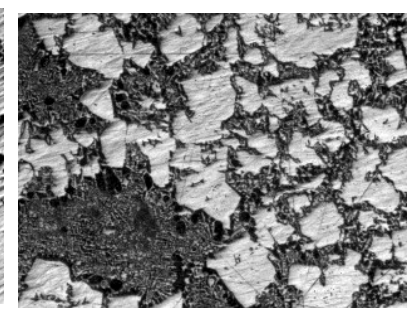

b
Fig.7. Fragmentation of the primary phase due to rotation stirring, a) $85 \mathrm{rpm}$ and b) $115 \mathrm{rpm}$

In microstructure figure, The $\mathrm{Bi}$ primary phase is shown as white grain. Rotation stirring can cause the primary phase break into fragments. It can be seen in Figure 7, The higher of the speed rotation, more grain/dendrite structure may be broken and distribute into different sizes. As explained in macrostructure part, that the higher rotation speed could make the Bi primary phase more distance and emerge spaces without $\mathrm{Bi}$ primaty phase, It is shown in Figure.7 as well. In the space appear Sn-rich phase, which is mark as black phases. The application of rotation stirring may cause solid solution phase $\mathrm{Sn}$-rich phase appear.
Macrosegregation refers to spatial variations in composition that occur in casting ingot. The distribution of solute will be different in relative large scale. EDX/SEM equipment can measured the composition of $\mathrm{Sn}$ in Alloy. In this research the distribution of $\mathrm{Sn}$ as a solute in alloy can be more homogen and closer to nominal composition in rotation stirring condition 85 $\mathrm{rpm}$ and performed at temperature $150^{\circ} \mathrm{C}$, as seen in Figure 8 and Figure 9.

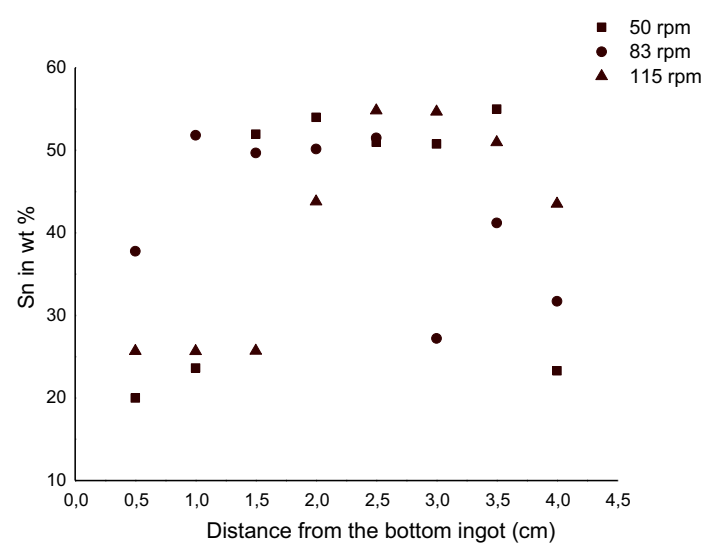

Fig.8 Distribution Sn with Rotation Stirring at temperature $180^{\circ} \mathrm{C}$

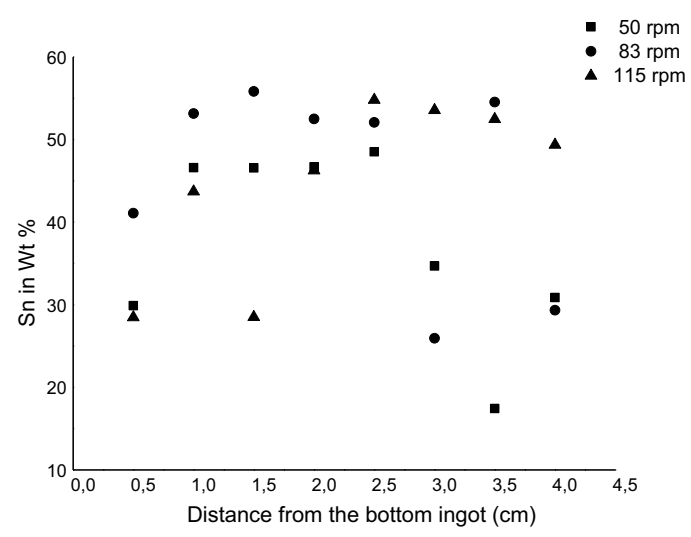

Fig.9. Distribution Sn with Rotation Stirring at temperature $150^{\circ} \mathrm{C}$

\section{Conclusion}

In this study, rotation stirring is used as an attempt to reduce macrosegregation in ingot. Base on the result of experiment, rotation stirring can give a force to raise and spread denser primary phase in remain eutectic liquid. It is proved by the large of primary phase zone become higher from $540 \mathrm{~mm}^{2}$ to $830 \mathrm{~mm}^{2}$. But it is still not enough to make the structure in ingot more uniform with this condition. The appropriate selection for temperature and speed is necesarry to obtain a good result. Generally stirring using rotation method can lead more uniform macrostructure in ingot but alternative process should be considered to get better results.

This work has been supported by Ministry of Research, Technology and Higher Education through the competitive grant. Author also want to thank to PT Timah (Persero) Tbk 
and PT Fajar Mas Murni. Both of them have supported us for availability of material and examination.

\section{REFERENCES}

[1] C. Beckermann, "Macrosegregation," ASM Handbook, Vol. 15 Cast., vol. 15, pp. 348-352, 2008.

[2] D. M. Stefanescu, Science and Engineering of Casting Solidification, 2nd editio. Newyork: Sprnger, 2009.

[3] R. Mehrabian, M. Keane, and M. C. Flemings, "Interdendritic Fluid Flow and Macrosegregation ; Influence of Gravity," Metall. Trans., vol. 1, no. May, 1970.

[4] W. Q. Zhang, Y. S. Yang, Y. F. Zhu, and Q. M. Liu, "Structural Transition and Macrosegregation of $\mathrm{Al}-\mathrm{Cu}$ Eutectic Alloy Solidified in the Electromagnetic Centrifugal Casting Process," Metall. Mater. Trans. A, vol. 29, no. January, pp. 1-5, 1998.

[5] M. J. Stewart, L. C. Macaulay, and F. Weinberg, "Macrosegregation in Castings Rotated and Oscillated During Solidification," Metall. Trans., vol. 2, no. January, pp. 169-173, 1971.

[6] Y. M. Zulaida, "The Influence of Cooling Rate on Macrosegregation in Bi-Sn Alloy," $A d v$. Mater. Res., vol. 1112, pp. 502-505, 2015.

[7] Y. M. Zulaida and Suryana, "Macrosegregation and Dendritic structure formation in different solute composition," in AIP conference Proceedings, 2016, vol. 20011.

[8] O. Gusakova, V. Shepelevich, and L. Scherbachenko, "Effect of Melt Cooling Rate on Microstructure of $\mathrm{Sn}-\mathrm{Bi}$ and $\mathrm{Sn}-\mathrm{Pb}$ Eutectic Alloys," Adv. Mater. Res., vol. 856, pp. 236240, 2013. 